\title{
Automated Trolley for Shopping
}

\author{
Rajesh Nayak $^{1}$, Ravi S Raikar ${ }^{2}$, Yogendra ${ }^{3}$, Vishwas $^{4}$ \\ Student, E\&C, SMVITM, Bantakal, Udupi, India ${ }^{1,2,3,4}$
}

\begin{abstract}
Shopping mall is a place where people get their daily necessities. We can see huge crowd at these malls on holidays and weekends. People purchase different items and put them in trolley. After completion of purchases, one needs to go to billing counter for payments. At billing counter the cashier prepare the bill using bar code reader which is very time consuming process and results in long queue at billing counter. There demand for quick and easy payment of bills in shopping malls. To overcome these problems we have designed a smart trolley. The Automated Shopping Trolley is a Smart Trolley which integrates with Barcode Scanners, Arduino, GSM module, Weighing Sensor in it. The scanned items by the customer which will automatically log into the database and thereby can generate bill for items purchased. The weighing sensor which will check the weight of the items send to the database. These modules are integrated into an embedded system and are tested to satisfy the functionality.
\end{abstract}

Index Terms: Arduino, Barcode scanner, GSM Module, Weighing Sensor.

\section{INTRODUCTION}

In recent years a deep structural change has occurred, with consequences on economic growth and society, especially in factors such as territorial occupation, urbanization, openness to global markets, demography, family structures and cultural and consuming patterns. Innovations in communication and information technologies have caused revolutions in values, knowledge and perceptions in practically all areas of human understanding, deeply carving the so-called "Age of Information and Knowledge". The grocery industry sector is nowadays extremely important in worldwide economy, with its recent evolution in technological, political, social and economic terms making it one of the most convenient and diverse businesses across the globe. Businesses have evolved from the sharing and coordination of information to the sharing of knowledge and advanced cooperation practices. The emergence of new technologies, such as Radio Frequency Identification (RFID) and wireless networks, makes the traditional retail processes faster, transparent and efficient. The technology represents to retailers an opportunity to reduce costs and to improve services, allowing to attend clients quickly, precisely and supplying personalized services. The advances in manufacturing, distribution and information combined with the urbanization of modern society and socio-demographical changes created the so-called new consumer. The consumer has a deeper understanding in comparing product costs is more versatile in brand preferences shows little loyalty to retailers has great expectations in services and client regard is selfsufficient and is more demanding towards supplied information. There was clear control transference from the manufacturers and retailers to the consumer. Strong competition between larger retail chains caused the minimization of profit margins as a form of keeping aggressive prices and winning more clients. In the modern world, shopping mall is a place where people get their daily necessities ranging from food products, clothing, electrical appliances etc. Every supermarket and hypermarkets employ shopping baskets and shopping trolleys in order to aid customers to select and store the products which they intend to purchase. The customers have to drop every product which they wish to purchase into the shopping cart and then proceed to checkout at the billing counter. The billing process is quite tedious and highly time consuming and has created the need for shops to employ more and more human resource in the billing section, and yet waiting time remains considerably high. In this project, we seem it fit to propose the "Intelligent Shopping Basket" which aims to reduce ,and possibly eliminate the total waiting time of customers, lower the total manpower requirement and expenses for markets and increases efficiency overall. In a world where technology is replacing the ways we pursue everyday activity, the future of the retail industry also lies in more and more automated devices. In this system customer will have information about price of the item and also brief about the product. This system will save time of the customers and manpower required in the mall and makes easy billing. The following part of the paper is organized as follows. The related work is discussed in chapter2. Details of proposed model in the chapter3. Flowchart and Algorithm is included in the chapter4. Results are shown and discussed in chapter 5. The conclusion is discussed in the chapter 6.

\section{RELATED WORKS}

In J. Thangakumar[1] Automated Shopping cart system integrates a Shopping cart (trolley) with 2 sets of barcode scanners placed at 2 different checkpoints. The entry \& exit point respectively. It facilitates the user to self-scan the barcode of the purchased products which he intends to purchase. Wrongful entries can be corrected by making use of a 
keypad that changes the functionality of the machine from addition of products to removal of products and activates the other barcode scanner at the opposite end. The main drawback of the project is using two barcode scanners and a gate like structures to cover trolley gate is very difficult to take out the product in cash counter. In Ankit Anil Agarwal [2] market visitor who intends to use Smart Cart system registers and creates an account in the website provided by the market. After that, this person transfers money into this account via internet banking or other sources. Therefore, the smart cart user will acquire some virtual cash in his/her market account. The value of this money and personal information along with purchase history will be stored in the Cloudant database. Market visitor can look at this information in the market website. The drawback of the system is user should have account in super market. In H. Karl and A. Willig [3] this application creates an automated central bill system for supermarkets and mall. Using PID, customers no need to wait near cash counters for their bill payment. Since their purchased product information is transferred to central billing system. Customers can pay their bill through credit/debit cards. The 8 - microcontroller used here has the capability of receiving 8-bit data from RFID reader. The AT89S52 doesn't have inbuilt I2C protocol, programmer has to create a separate EMBEDDED C program to communicate with EEPROM. This may create some difficulties in writing program for programmers to synchronize with EEPROM. Some of other microcontrollers and microprocessors have inbuilt I2C protocol features. Those can be used as further improvement in efficiency and compatibility of this application.

\section{PROPOSED MODEL}

For the product identification barcode is used and a barcode is visual representation of data that is scanned and interpreted for information. Each barcode contains code which works as tracking technology for products, is represented in sequence of lines. This barcode having the several advantages over the others. The barcodes are less expensive than the RFID tags and can directly print on the plastic or paper materials. And are gives more accuracy than other. Barcode scanner gives the some more advantages, it saves the time as it scan the barcode within fraction of seconds and it will not do mistake while reading the barcodes, the internal operations of the barcode which is of smoothly and thereby customer can also deal with it easily.

And this system uses the Arduino. Arduino simplifies the amount of hardware and software development need to in order to get a system running. This Arudino hardware platform already has the power and reset circuitry setup well as circuitry for program and communicate with the other devices over the USB. In addition to this Arduino provides the more number of libraries to make programming. More useful things such as being able to set I/O pins to PWM at certain duty cycle using a single command or doing serial communication.

The Automated Shopping cart system integrates a Shopping trolley with 1 barcode in entry position. It facilitates the user to self-scan the barcode of the purchased products which he intends to purchase. Customer should scan the barcode and put into a cart. The added items weight will check by the weighing sensor maintained at platform of the cart. This weight will continuously send to the database. With the weight also the product number also sent to the server. These parameters are checked against the product barcode and weight which already updated in the server database. The block diagram for the trolley side section is shown in the figure 1.

\section{BLOCK DIAGRAM:}

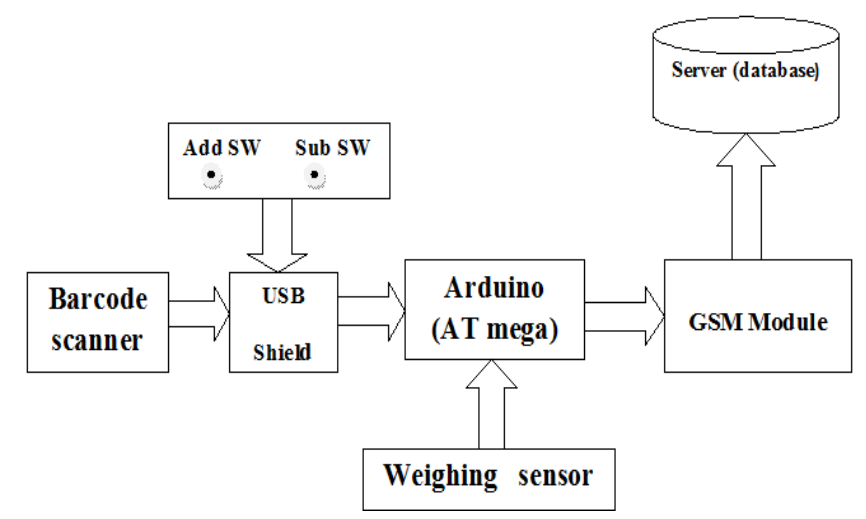

Fig. 1 Block diagram of trolley section.

If the customer wishes to remove the item from the cart then customer can take out the product he does not want to purchase, then customer need to scan the product which he/she wants to takeout and should press the Sub SW. which is already attached to the cart system. 
UGC Approved Journal

IJIREEICE

\section{International Journal of Innovative Research in} Electrical, Electronics, Instrumentation and Control Engineering

ISO 3297:2007 Certified

Vol. 5, Issue 6, June 2017

The Billing section block diagram is shown in the figure 2. The billing section computer is connected to server database. In the server the purchased product weight and it's product number are checked against the database product parameters of the products. If there is any mismatch then the error message will generate at the billing system.

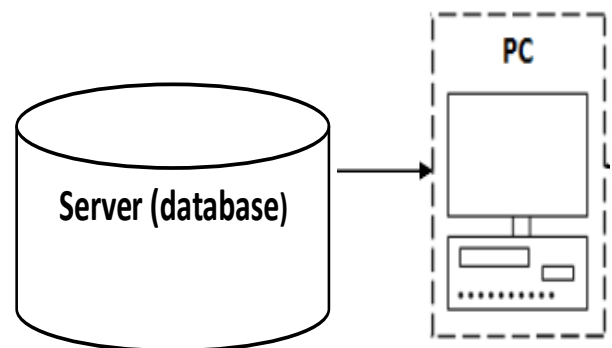

Fig. 2 Block diagram of billing system

The system components are shown in the figure 3. It's having the Arduino, GSM module and the ADC converter from the weighing sensor to the Arduino.

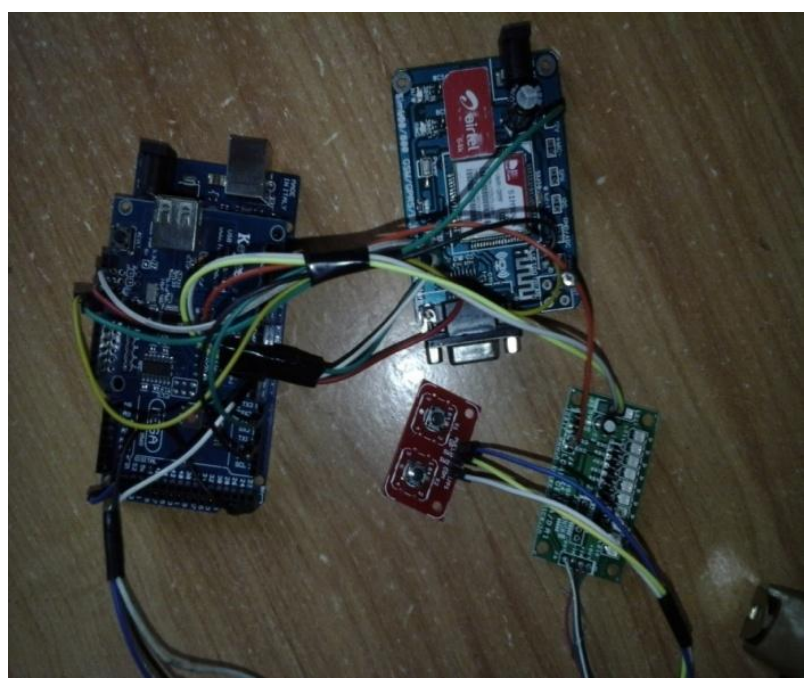

Fig.3 System Components

IV. FLOWCHART AND ALGORITHM

\section{FLOWCHART}

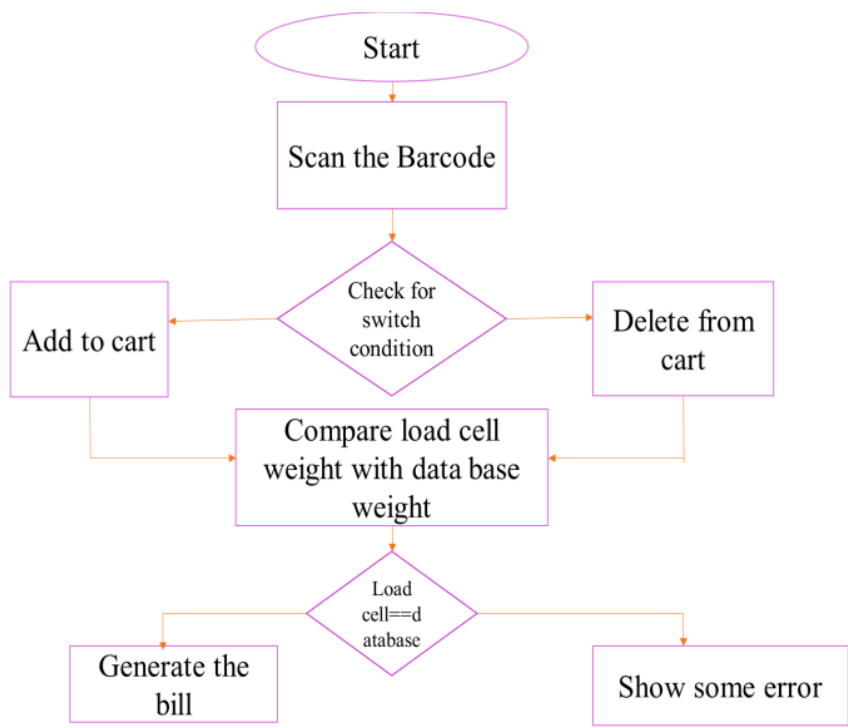


Vol. 5, Issue 6, June 2017

\section{ALGORITHM}

1. The first step is starts with the scanning of the barcode of the product.

2. Then system need to check for the switch condition is there Add SW. is pressed or the Sub SW. is pressed.

3. If any switch is pressed then it need to compare for the load cell weight with the database updated product weight.

4. If the load cell weight is matching with cart's product weight then it need to allow customer to proceed with purchase.

5. If there is mismatch in the compared weight then it will generate the error message.

6. Finally it will generate bill, and will send the message to customer about the shopping, purchased number of products and total bill of products.

\section{RESULT AND PERFORMANCE ANALYSIS}

The product barcode given in table I are used to indicate distinctive products being shopped. As the barcode scanner read the product, details were displayed on the display unit. The product details of the shopped items were temporarily stored in the local memory. Once the shopping "Complete" the memory contents were read and billing was done. The same product information data was sent back to the server to update the inventory.

The following tests were used in the integrated system testing to prove the working of the developed system.

1. The shopping cart system and server communication using the GSM module.

2. Scanning the barcode and synchronizing with the database.

3. Display the product details as shown above on the computer screen of the billing system.

4. Adding the product or removing the products as the customer does and replicate in the database.

5. Generating the billing after customers shopping.

6. Sending the billing message to the customers provided mobile number.

All test cases were successfully tested. The system developed is user friendly, there is no special training is required to use the automated shopping cart.

\section{CONCLUSION}

Objectives were successfully achieved in the prototype model. The developed model is easy to use, low-cost and does not need any special training. This project report reviews and exploits the use of barcode technology which are used for product identification. We have also learned the architecture of the system that can be used in the shopping systems for intelligent and easy shopping in the malls to save time, energy and money of the consumers. There are a few challenges/drawbacks that can be resolved to make proposed system more robust. This issue will have to be resolved specifically with respect to billing to promote con card to browse the offers, deals and facility of payment within the cart by using swapping card can be used to make cart more advance provide better consumer experience.

\section{ACKNOWLEDGMENT}

I express my deep sense of gratitude and indebtedness to our institution "SHRI MADHWA VADIRAJA INSTITUTE OF TECHONOLGY \& MANAGEMENT", which provided me the opportunity to fulfill our cherished goals. I extend my sincere thanks and regards to Dr. THIRUMALESHWARA BHAT, Principal SMVITM for giving us this opportunity to carry out this work in the college. I sincerely acknowledge the encouragement and support given to us by our guide \& project coordinator Mr. RANJITH BHAT, Associate professor, dept. of ECE, SMVITM and Dr. BALACHANDRA ACHAR H. V., HOD, Dept. of ECE, SMVITM in completion of my paper.

\section{REFERENCES}

[1].J. Thangakumar, S. Sainath, K. Surender, V. Vikram Arvind, “Automated Shopping Trolley for Super Market Billing System”International Journal of Computer Applications (0975 - 8887) International Conference on Communication, Computing and Information Technology (ICCCMIT-2014)

[2].Ankit Anil Agarwal, Saurabh Kumar Sultania, Gourav Jaiswal and Prateek Jain on "RFID Based Automatic Shopping Cart" in Control Theory and Informatics ; ISSN 2224-5774 (print) ISSN 2225-0492 (online), Vol 1, No.1, 2011

[3] H. Karl and A. Willig, "Protocols and Architectures for Wireless Sensor Networks," Chichester, England, 2005.

[4] J.Awati and S.Awati, "Smart Trolley in Mega Mall," in International Journal of Emerging Technology and Advanced Engineering Website: www.ijetae.com (ISSN 2250-2459, Volume 2, Issue 3, March 2012)

[5] Satish Kamble, SachinMeshram, Rahul Thokal, Roshan Gakre on "Developing a Multitasking Shopping Trolley Based On RFID Technology" in International Journal of Soft Computing and Engineering (IJSCE) ISSN: 2231-2307, Volume-3, Issue-6, January 2014

[6] Raju Kumar, K. Gopalakrishna, K. Ramesha on "Intelligent Shopping Cart" in International Journal of Engineering Science and Innovative Technology (IJESIT) Volume 2, Issue 4, July 2013. 